\title{
Historical perspectives of The American Association for Thoracic Surgery: Joel D. Cooper
}

\author{
Ikenna C. Okereke, MD, FACS, ${ }^{a}$ Stephen D. Cassivi, MD, ${ }^{b}$ and Marc R. Moon, MD
}

\author{
From the ${ }^{\mathrm{a} D i v i s i o n}$ of Cardiothoracic Surgery, University of Texas Medical Branch, Galveston, Tex; ${ }^{\mathrm{b}}$ Division of \\ Thoracic Surgery, Mayo Clinic, Rochester, Minn; and ${ }^{\mathrm{c}}$ Division of Cardiothoracic Surgery, Washington \\ University School of Medicine, St Louis, Mo. \\ Disclosures: Authors have nothing to disclose with regard to commercial support. \\ Address for reprints: Ikenna C. Okereke, MD, FACS, Division of Cardiothoracic Surgery, University of Texas \\ Medical Branch, Galveston, TX 77555 (E-mail: ikokerek@utmb.edu). \\ J Thorac Cardiovasc Surg 2016;151:1440-3 \\ $0022-5223 / \$ 36.00$ \\ Copyright (C) 2016 by The American Association for Thoracic Surgery \\ http://dx.doi.org/10.1016/j.jtcvs.2016.03.058
}

Joel David Cooper (Figure 1), the 84th President of The American Association for Thoracic Surgery, has been a leader and a pioneer in the field of thoracic surgery. His accomplishments and innovation in all aspects of thoracic surgery have in large part shaped the practice of thoracic surgery today. Dr Cooper was born in Charleston, West Virginia, on January 2, 1939. His father was an orthodox Rabbi, and his mother was very active in the community and an amazing baker who wrote several cookbooks. Her most recent, Still Cooking at One-Hundred, was published in 2011 by the Ladies' Auxiliary of B'nai Jacob, his father's synagogue. ${ }^{1}$ Dr Cooper developed an interest in the sciences at an early age and was a self-proclaimed "gadgeteer." He used his childhood chemistry set to design small flash powder explosives that one day, much to his mother's chagrin, completely singed off his eyebrows and hair when the electrical circuit he built to set off the flash powder misfired. Dr Cooper remembers the privileges of being the son of the town's rabbi. ${ }^{2}$ Because of his father's connections, he was able to get things that others students may not have had access to. For his high school science project, he wanted to measure acceleration in a vacuum and was able to get an old vacuum pump and 15-foot heavy glass cylinder from one of his father's congregants who owned a chemical supply house (Figure 2). Fishing was the family holiday 1 month each summer (Figure 3). Dr Cooper was the one who cleaned the fish and remembers taking the heart out, putting it in saline, and watching it beat for a few hours. That combined with a nearly fatal case of appendicitis as a child are thought to have been his motivation to become a surgeon.

Dr Cooper completed his undergraduate studies at Harvard College, where he graduated summa cum laude and Phi Beta Kappa with a Bachelor of Arts degree in Chemistry. Thereafter, he attended Harvard Medical School and earned cum laude distinction upon graduation. He stayed in Boston for his residency in general surgery at the

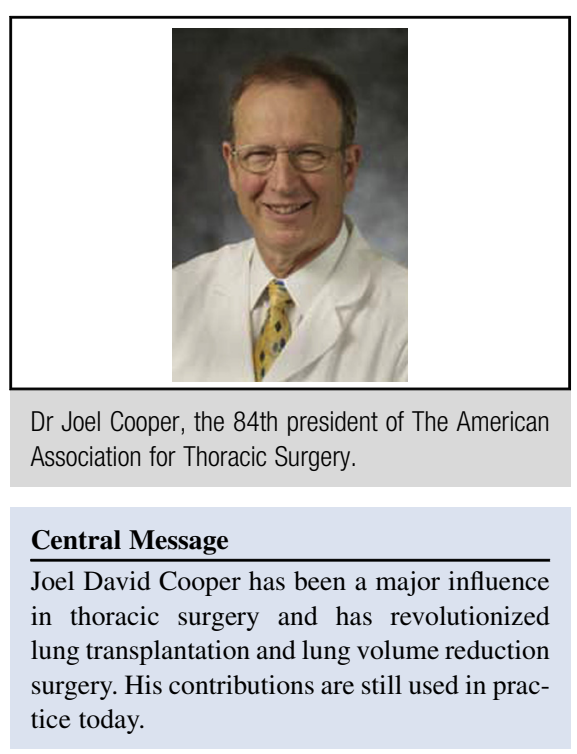

Massachusetts General Hospital. In November 1965, he stuck himself while drawing fresh blood from a donor to prime the pump for open surgery and contracted hepatitis. As a result, he was taken off the clinical service and sent to pathology to perform autopsies. During that time, Dr Hermes Grillo asked Dr Cooper to investigate the mechanism of late tracheal stenosis after prolonged ventilation. ${ }^{3}$ Dr Cooper made a manometer to measure pressure in the cuffs of patients who died with an endotracheal tube in place. He found the pressure to be quite high. It took a great deal of force to occlude the trachea, and the high-pressure cuffs became very rigid, stretching and ultimately damaging the trachea. This led to the development of low-pressure cuffs that would conform to the trachea but not cause damage. That experience sparked his interest in thoracic surgery.

After finishing his general surgery residency, Dr Cooper departed for England. While there, he served as a Senior Registrar in Thoracic Surgery at the Frenchay Hospital in Bristol with Ronald Belsey for 6 months and completed a fellowship in the Department of Medicine at the Hammersmith Hospital in London with Dr John West, a renowned physiologist. Thereafter, he completed his thoracic training at the Massachusetts General Hospital. Dr Cooper joined the staff at the University of Toronto in 1972, where there was a focused unit in general thoracic surgery under the direction of Dr Griff Pearson (70th American Association for Thoracic Surgery President). Dr Cooper was attracted to the 


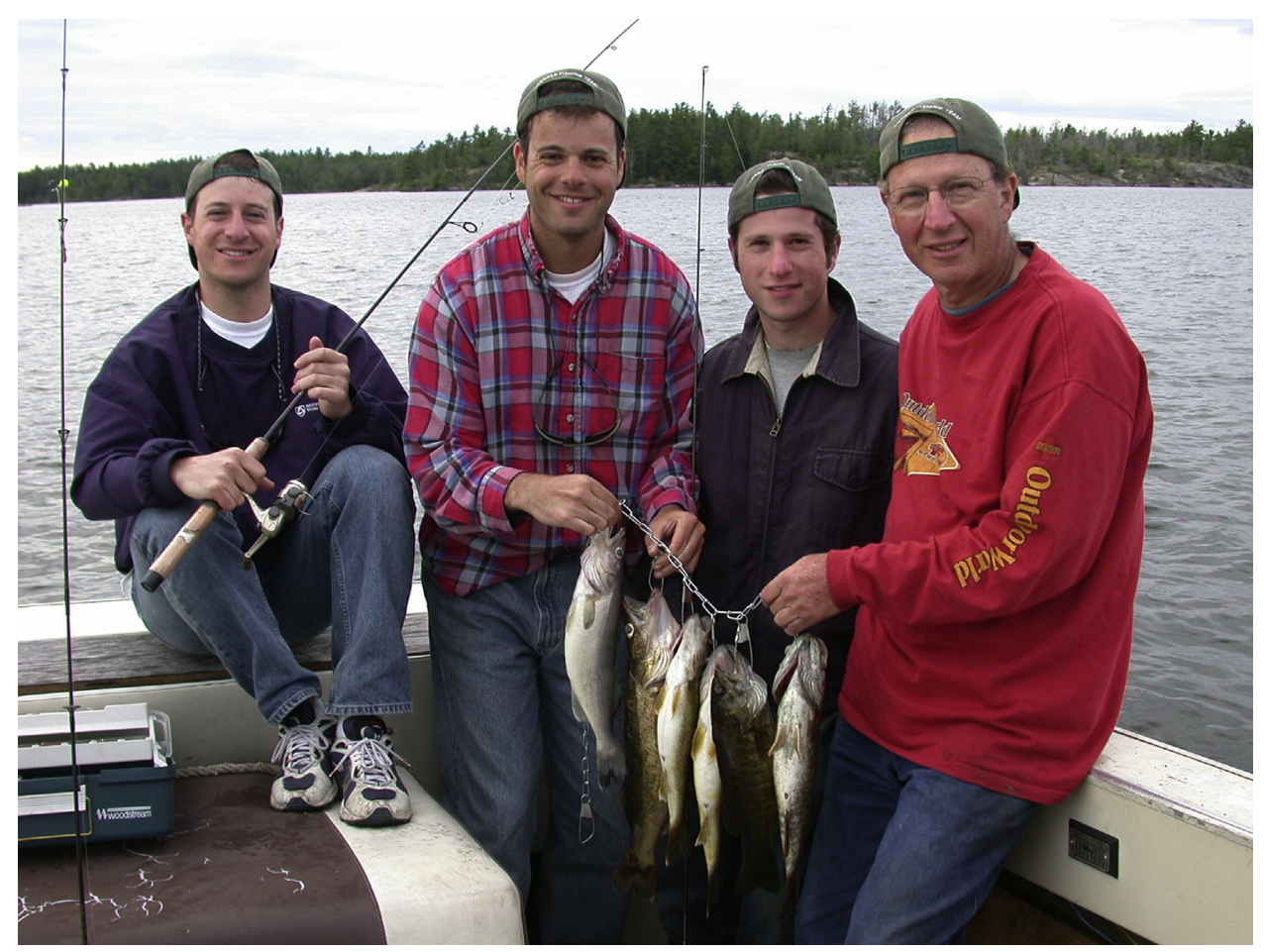

FIGURE 1. Dr Cooper enjoying his favorite nonsurgical pastime with 3 of his 4 sons.

unit in Toronto because it was a regional center that attracted general thoracic patients from across Canada, something that did not exist in the United States at the time. While in Toronto, Dr Cooper worked with others, including Dr Alec Patterson (90th American Association for Thoracic Surgery President), to develop the field of thoracic transplantation and find the solution for successful lung transplantation. Until then, previous attempts worldwide at lung transplantation had failed. ${ }^{4,5}$ As Dr Cooper himself said, "It was thought that the bronchus might just be the Achilles' heel of transplantation, and it just was an insoluble problem." ${ }^{, 6}$ It was only after multiple animal experiments and a considerable amount of effort that the Toronto group was able to show a possible pathway toward a successful transplant. ${ }^{7}$

Dr Cooper and colleagues were able to develop 2 major innovations related to lung transplantation. Their first innovation was to change dramatically the technical aspect of the operation. Bronchial dehiscence and failure of the bronchial anastomosis to heal had typically been major and frequently encountered complications. Dr Cooper addressed this concern by wrapping a pedicled graft of omentum around the bronchial anastomosis. The second major step that Dr Cooper took was to change the immunosuppression regimen. High doses of prednisone had been used formerly, but these doses significantly hindered healing of the anastomosis. ${ }^{8}$ Dr Cooper used cyclosporine as part of the immunosuppressive regimen. These 2 steps led to the first successful lung transplant at the University of Toronto on June 7, 1983. ${ }^{9}$ Tom Hall, a patient with endstage lung disease secondary to pulmonary fibrosis, died 6 years later but was highly functional after the transplant. The first successful double-lung transplant also was performed by the Toronto Lung Transplant Group on November 26, 1986, in a 42-year-old woman with $\alpha_{2}$-antitrypsin deficiency. ${ }^{10}$ Since then, tens of thousands of lung transplantations have been performed successfully, but the entire field owes gratitude to Dr Cooper, who helped launch these efforts in what was previously thought to be an impossible operation to perform safely in patients.

Dr Cooper also investigated additional surgical treatments for patients with end-stage lung disease. He thought that removal of the most damaged aspects of each lung, lung volume reduction surgery, was a procedure that could reestablish functional capacity in these patients. Although lung volume reduction surgery had been initially used and described by Brantigan and colleagues ${ }^{11}$ at the University of Maryland in the 1950s, this procedure had not gained much popularity, with a limited number of cases performed in the United States annually. Through Dr Cooper's efforts, the number of lung volume reduction surgeries increased dramatically. In similar fashion to his work in lung transplantation, Dr Cooper advanced this procedure with the introduction of buttressed staple loads to decrease the incidence of persistent air leak after the procedure. ${ }^{12}$ 


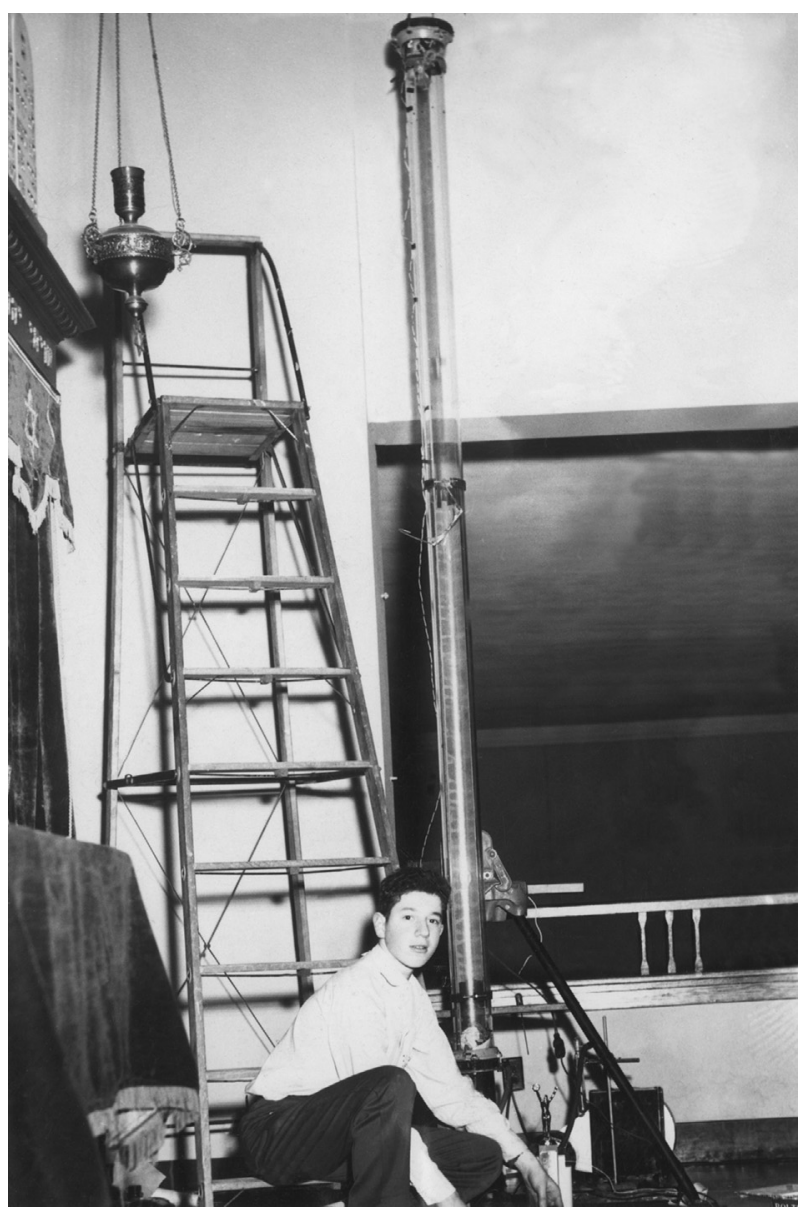

FIGURE 2. Dr Cooper's high school science project to measure the effect of gravity on acceleration.

Dr Cooper moved to Washington University in St Louis to lead the Section of Thoracic Surgery in 1988. He became the Evarts A. Graham Professor of Surgery and the Chief of the Division of Cardiothoracic Surgery in 1997. As apparent as his clinical excellence and achievements were, Dr Cooper was widely known in St Louis as an unparalleled educator. Dr Cooper placed great importance in teaching residents the practice of thoracic surgery both in and out of the operating room. He also spent a significant amount of time with the medical students at Washington University School of Medicine. His passion and expertise in thoracic surgery were remarkable, and he would take time out of his schedule daily to interact with the students and teach them pearls of wisdom that could not be found in textbooks. His enthusiasm for his practice and in educating were responsible for many medical students ultimately deciding to choose thoracic surgery as their career. "I personally can say that my interaction with Dr Cooper as a medical student was the principal reason I became a thoracic surgeon, and I am grateful to this day for the opportunity to have interacted with him at such a critical time in my training" (Ike

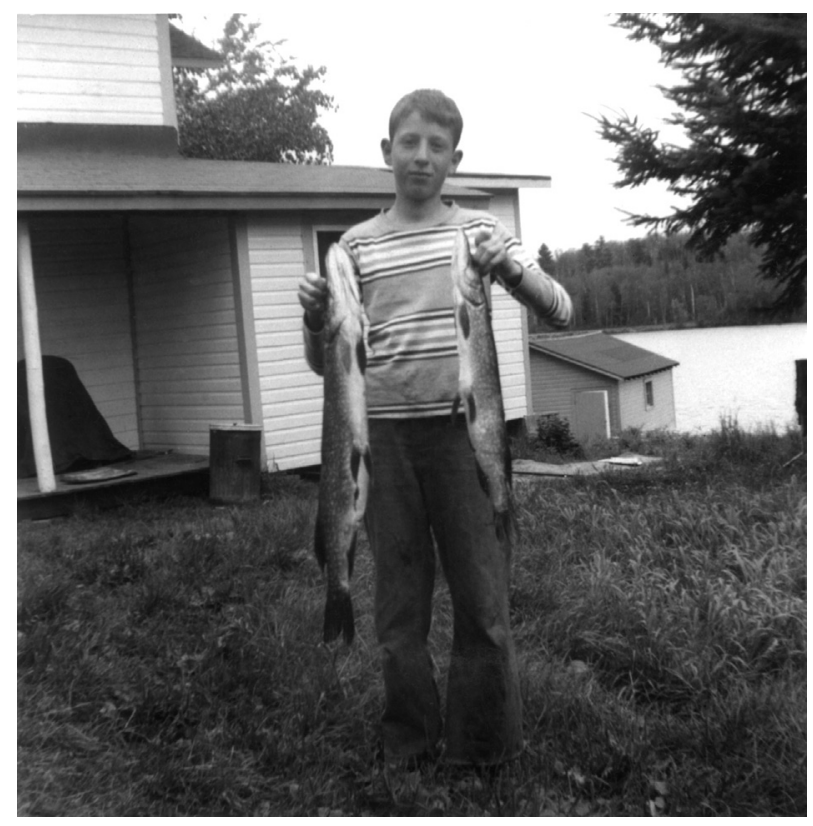

FIGURE 3. Dr Cooper fishing at Blue Sea, Quebec, in 1952.

Okereke). Dr Cooper recalled a philosophy professor in college who said, "What we want for ourselves is success. What we want for our children is happiness." ${ }^{2}$ Dr Cooper now thinks that we can have both. Dr Cooper met his wife Janet during college and has been married now for more than 52 years. "I couldn't have had my career without my wife," he says. Dr and Mrs. Cooper have 4 sons, and he credits her with their successful upbringing, noting that his most important contribution was "perhaps staying out of her hair!" (Figure 4).

In 2005, Dr Cooper moved to the Hospital of the University of Pennsylvania to lead the Division of Thoracic Surgery, where he remains clinically active today. Joel Cooper has forged and shaped the field of thoracic surgery during his long and fruitful career. Before minimally invasive thoracic surgery had gained widespread acknowledgment and prevalence, Dr Cooper used a transcervical approach to resect the thymus gland with excellent results. ${ }^{13} \mathrm{He}$ has resurrected procedures that were once thought to be useless or impossible to perform successfully and has mentored innumerable cardiothoracic surgeons over the last 4 decades, always with a sense of grace and humility. He has received multiple prestigious awards, including the Jacobson Innovation Award from the American College of Surgeons, the Thomas E. Starzl Prize in Surgery and Immunology from the University of Pittsburgh School of Medicine, and the Earl Bakken Scientific Achievement Award from the Society of Thoracic Surgeons. When talking to Dr Cooper, the excitement he possesses regarding thoracic surgery becomes evident instantly. We congratulate Dr Cooper for his many 


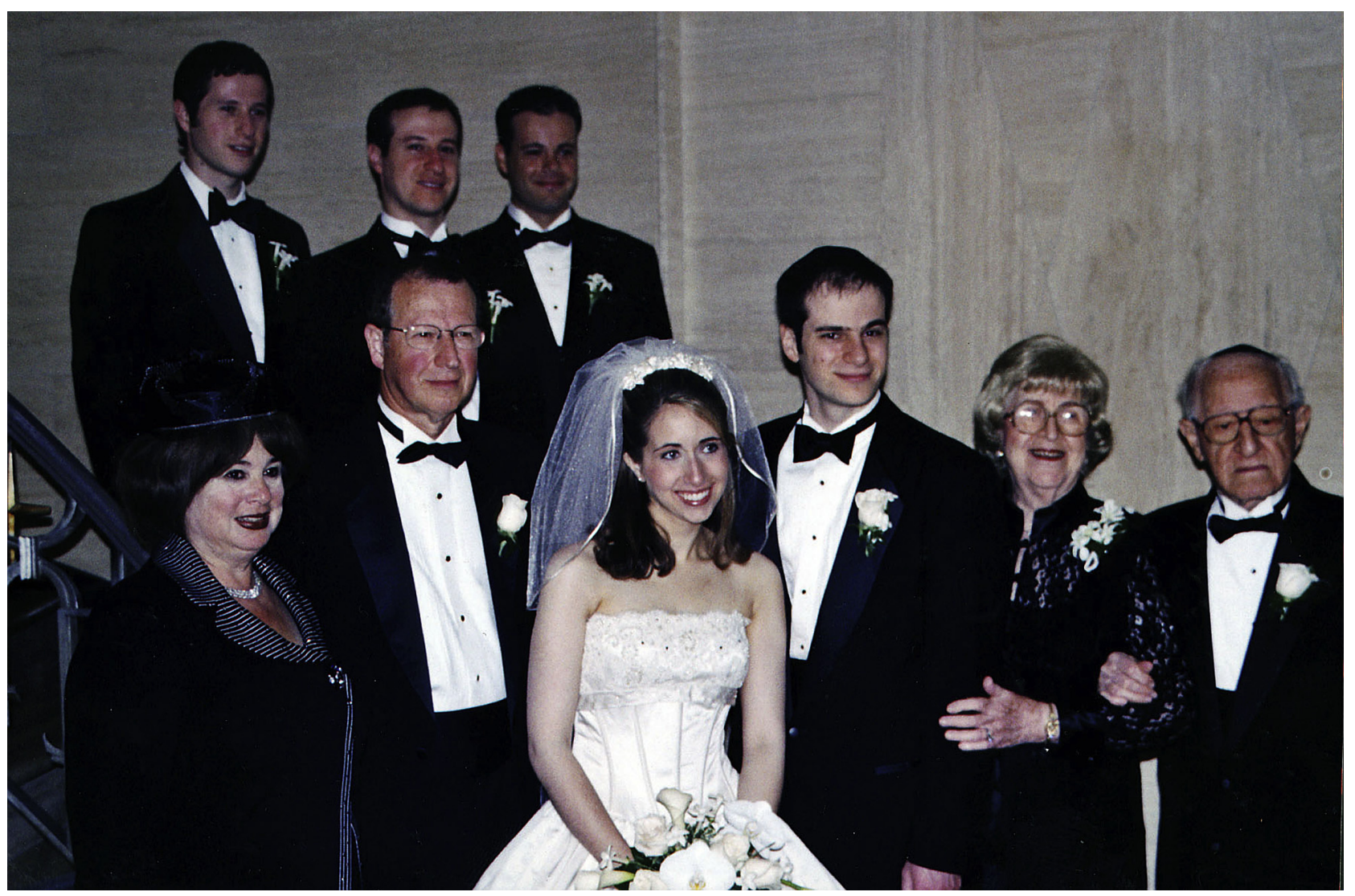

FIGURE 4. Dr and Mrs Cooper (left), Rabbi Samuel and Lillian Cooper (right), with sons Jordan, Joshua, and Jeremy (back) at the wedding of son Jonas to Carly in 2003.

contributions and tireless efforts to promote and develop the care of patients with thoracic diseases.

\section{References}

1. Cooper L. Still Cooking at One-Hundred. Charleston, WV: B'nai Jacob Ladies Auxiliary; 2011.

2. The American Association for Thoracic Surgery. AATS past president interview. February 15, 2012. AATS Centennial [pending publication].

3. Grillo HC, Cooper JD, Geffin B, Pontoppidan H. A low-pressure cuff for tracheostomy tubes to minimize tracheal injury. A comparative clinical trial. J Thorac Cardiovasc Surg. 1971;62:898-907.

4. Lansman SL, Ergin MA, Griepp RB. The history of heart and heart-lung transplantation. Cardiovasc Clin. 1990;20:3-19.

5. Benfield JR, Wain JC. The history of lung transplantation. Chest Surg Clin NAm. 2000;10:189-99.

6. ATSNews. Joel D. Cooper: Surgeon of the world's first successful lung transplantations. November 1, 2013. Available at: http://news.thoracic.org/joel-d-coopersurgeon-of-the-worlds-first-successful-lung-transplantations/. Accessed April 1, 2016.
7. Lima O, Cooper JD, Peters WJ, Ayabe HA, Townsend E, Luk SC, et al. Effects of methylprednisolone and azathioprine on bronchial healing following lung autotransplantation. J Thorac Cardiovasc Surg. 1981;82: 211-5.

8. Goldberg M, Lima O, Morgan E, Ayabe HA, Luk SC, Ferdman A, et al. A comparison between cyclosporine A and methylprednisolone plus azathioprine on bronchial healing following canine lung autotransplantation. J Thorac Cardiovasc Surg. 1983;85:821-6.

9. Toronto Lung Transplant Group. Unilateral lung transplantation for pulmonary fibrosis. N Engl J Med. 1986;314:1140-5.

10. Patterson GA, Cooper JD, Dark JH, Jones MT. Experimental and clinical double lung transplantation. J Thorac Cardiovasc Surg. 1988;95:70-4.

11. Brantigan OC, Mueller E, Kress MB. A surgical approach to pulmonary emphysema. Am Rev Respir Dis. 1959;80:194-206.

12. Cooper JD. Technique to reduce air leaks after resection of emphysematous lung. Ann Thorac Surg. 1994;57:1038-9.

13. Calhoun RF, Ritter JH, Guthrie TJ, Pestronk A, Meyers BF, Patterson GA, et al Results of transcervical thymectomy for myasthenia gravis in 100 consecutive patients. Ann Surg. 1999;230:555-61. 